\title{
A prática discursiva da escrita: entre a memória e o esquecimento
}

\author{
Ana Luisa Ribeiro Rodrigues de Sant'Ana*
}

\begin{abstract}
Resumo
Este ensaio versa sobre a prática discursiva da escrita. Aqui, é retomado um artigo preliminar nunca publicado produzido anteriormente. A proposta inicial para esse artigo era discutir o fenômeno da intertextualidade. A partir desse ponto inicial, debrucei-me sobre os diálogos que poderiam ser estabelecidos entre ideias advindas do Círculo de Bakhtin sobre o discurso de outrem e o conceito de intertextualidade assentado no quadro da Linguística Textual. Para ilustrar o fenômeno e a discussão, eu tomei os poemas "Canção do Exílio", de Gonçalves Dias, e "Canção do Exílio", de Murilo Mendes. Neste presente ensaio, alargo essa discussão à luz dos pressupostos teóricos da Análise do Discurso Francesa de memória, esquecimento, deriva, identificação, desidentificação, formação discursiva, ordem do discurso, além de propor, também, uma reflexão da minha própria prática de reabrir o artigo para tecer novos fios discursivos.

Palavras-chave: Escrita. Prática discursiva. Análise do Discurso Francesa.
\end{abstract}

* Pontifícia Universidade Católica de Minas Gerais (PUC Minas). Mestre em Linguística e Língua Portuguesa. Professora de Produção de Textos na Educação Básica. ORCID: https://orcid.org/0000-0002-3362-0279.

Cadernos CESPUC de Pesquisa. Série Ensaios. n.39, 20 Sem./2021, p. 109-122.

e-ISSN: 2358-3231 (OJS). Recebido em: 19/04/2021. Aceito em: 03/12/2021. 


\title{
The discursive practice of writing: between memory and forgetting
}

\author{
Ana Luisa Ribeiro Rodrigues de Sant’Ana
}

\begin{abstract}
This essay discusses the discursive practice of writing. Here, it resumes a preliminary article, never published, produced for a course in the Language Degree Course. The initial proposal for this article was to discuss the phenomenon of intertextuality. From this starting point, I looked into the dialogues that could be established between ideas coming from Bakhtin's Circle about the discourse of others and the concept of intertextuality based on the framework of Textual Linguistics. To illustrate the phenomenon and the discussion, I took the poems "Canção do Exílio", by Gonçalves Dias, and "Canção do Exílio", by Murilo Mendes. In this present essay, I extend this discussion in light of French Discourse Analysis theoretical assumptions of memory, forgetting, drift, identification, unidentification, discursive formation, order of discourse and I also propose a reflection of my own practice of reopening the article to weave new discursive threads.
\end{abstract}

Keywords: Writing. Discursive practice. French Discourse Analysis.

Cadernos CESPUC de Pesquisa. Série Ensaios. n.39, $2^{\circ}$ Sem./2021, p. 109-122.

e-ISSN: 2358-3231 (OJS). Recebido em: 19/04/2021. Aceito em: 03/12/2021. 


\section{Iniciando a trilha}

Abro este texto com estes certeiros dizeres de Orlandi (2001):

[...] um mesmo texto volta sempre, fazendo seu retorno em várias retomadas por um sujeito autor que trabalha diferentes formulações (versões) em uma história inacabada de diferentes textualizações possíveis (ORLANDI, 2001, p. 96).

De antemão, já justifico que abrir o texto com uma citação não foi uma escolha arbitrária, visto que ela traduz a trilha que eu me propus a percorrer. Apesar de iniciar um movimento de justificativa, não vou me alongar nisso neste momento, pois acredito (e espero!) que essa escolha fique mais clara à medida em que as discussões que serão postas à cena forem ganhando corpo.

O primeiro passo necessário para percorrer essa trilha é fazer uma viagem, nem tão distante assim, ao ano de 2015. Eu estava, exatamente, no terceiro período da graduação do curso de Letras da PUC-MG e fui solicitada, em uma das disciplinas, ${ }^{1}$ a escrever um artigo científico que contemplasse o fenômeno da intertextualidade.

No artigo que eu iniciei a escrita (retomarei esse ponto mais adiante), debrucei-me sobre os diálogos que poderiam ser estabelecidos entre a discussão de Volóchinov (2017) sobre o discurso de outrem ${ }^{2}$ e o conceito de intertextualidade trazido por Koch, Bentes e Cavalcante (2007), até porque, esses eram textos tomados para estudo na disciplina em questão. Para ilustrar o fenômeno e a discussão, eu tomei os poemas "Canção do Exílio”, de Gonçalves Dias, e “Canção do Exílio”, de Murilo Mendes.

Primeira parada: uma viagem ao ano de 2015

A primeira parada dessa trilha consiste em explicar o porquê dessa viagem no tempo e, agora, eu apresento uma reposta, buscando, também, aprofundar na justificativa para abertura deste texto que ensaiei fazer logo no início. Para isso, trarei alguns dizeres e reflexões de extrema relevância para os estudos da Análise do Discurso desenvolvidos por Indursky (2016) (que mantém um diálogo estreito com Orlandi em sua bibliografia). Em

\footnotetext{
1 Trata-se da disciplina "Estudos Linguísticos: princípios e processos de textualização"

2 Utilizarei a versão de "Marxisimo e filosofia da linguagem" publicada em 2017, em que a nomenclatura "discurso de outrem" é substituída por "discurso alheio".
} 
um texto no qual a autora se dedica a refletir sobre a prática da escrita, ela esclarece ao leitor que pretende desfazer a ilusão de fechamento do texto que o ponto final cria, embora reconheça que essa ilusão seja necessária. Indursky afirma, também, que o que a move, na escrita desse texto é:

a possibilidade que o sujeito-autor tem de ocupar o lugar discursivo do outro, do leitor, retornando a seu próprio texto para sobre ele fazer uma leitura desestabilizadora de seu efeito de completude, seja para se autocorrigir, seja para trazer outros fios discursivos que, por diversos motivos, não puderam ser contemplados anteriormente e tramá-los àqueles que aí já se encontravam. (INDURSKY, 2016, p. 31)

Esse é um ponto essencial da trilha para continuarmos percorrendo-a. Partindo dos pressupostos de que o fechamento de um texto não passa de uma ilusão e de que há sempre a possibilidade do sujeitoautor retomar o seu próprio texto ao assumir o lugar discursivo do outro, o que pretendo, neste texto, é assumir essa posição sujeito-autor e retomar o artigo que escrevi em 2015, trazendo novos fios discursivos e tramá-los juntos aos que já se encontravam naquele artigo. Foi motivada por essa defesa de Indursky (2016) sobre efeito de completude de um texto, o que pressupõe a incompletude, que, mais acima, pontuei que era um artigo que eu havia iniciado a escrita, artigo esse que eu tinha a ilusão de ter fechado ao colocar o ponto final e que vem agora ser retomado neste texto, o qual está sendo, também, só iniciado.

Feitas todas essas considerações, acredito que podemos prosseguir o percurso da nossa trilha que, a partir de agora, ficará mais longa e densa, mas também, instigante. Para apontar meu caminho agora, parafraseio Indursky (2016): estou abrindo o meu artigo de 2015 e fazendo dele um rascunho, desestabilizando, assim, sua provisória estruturação e seus possíveis sentidos, reescrevendo-os para iniciar a construção de um novo texto, buscando, novamente, o efeito/ilusão da estabilização. É justamente essas ações que constituem o jogo entre memória e esquecimento na escrita, condição constituinte dessa prática. 
Segunda parada: estabelecendo diálogos entre os conceitos de "discurso alheio" e interdiscursividade

Dando continuidade à nossa trilha, percorreremos, agora, o texto "Exposição do problema do 'discurso alheio", de Volóchinov (2017), que, como dito anteriormente, foi um dos estudos ${ }^{3}$ tomados por mim na produção do artigo. O autor postula que "o discurso alheio é o discurso dentro do discurso, o enunciado dentro do enunciado, mas ao mesmo tempo é também o discurso sobre o discurso, o enunciado sobre o enunciado" (VOLÓCHINOV, 2017). Em outros termos, o discurso alheio pode ser entendido como a apropriação que se faz de um discurso, incorporando-o ao seu próprio discurso. Trata-se, na realidade, de uma relação ativa entre esses discursos. Entretanto, é importante ressaltar que essa apropriação às vezes se dá de forma inconsciente e não pode ser arbitrária, na medida em que somos seres históricos inseridos em um contexto sócio-políticoeconômico-cultural e esse contexto orienta tanto a produção, quanto a recepção desses discursos.

Naquela época, restringi-me a apresentar o conceito de discurso alheio sem fazer reflexão alguma sobre esse conceito. Aqui, vou me aventurar a tecer alguns comentários a respeito, incorporando a esse texto novos fios discursivos. Por que nos apropriamos do discurso alheio e o repetimos como se fossem nossos? Indursky (2001) defende que não se trata de uma simples repetição, pois repetimos parafraseado. A autora aponta que, na verdade, a repetição deve ser entendida como uma reformulação do sentido do já dito em algum momento da história e do sentindo construído por nós no dito daquele momento da história. Segunda a autora, o motivo pelo qual repetimos tem uma dupla faceta: (i) repetimos para reiterar, consolidar a identidade do discurso em uma ordem discursiva ${ }^{4}$, esse movimento acontece quando nos identificamos com a formação discursiva ${ }^{5}$ na qual o discurso está inscrito e (ii) repetimos para descontruir, desmontar, deslocar os sentidos, colocando-os à deriva, já esse movimento ocorre quando nos

\footnotetext{
3 Na época da escrita do artigo, em 2015, foi tomada a seguinte versão: BAKHTIN, M. (VOLÓCHINOV). O discurso de outrem. In: Marxismo e filosofia da linguagem. São Paulo: Hucitec, 1990, p. 144-154

4 Neste texto, o conceito de ordem discursiva é tomado sob a perspectiva de Foucault. Para aprofundar nesse conceito, recorra a: FOUCAULT, Michel. Ordem do discurso (A). Edições Loyola, 1996.

5 Toma-se, aqui, o conceito de formação discursiva proposto por Foucault. Para aprofundar nesse conceito, recorra a: FOUCAULT, Michel. As formações

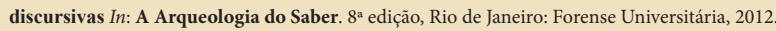


desidentificamos com a formação discursiva em que o discurso se insere. Percebemos, então, que há um trabalho discursivo do sujeito sobre/pela língua(gem) na negociação dos sentidos.

O conceito de discurso alheio discutido por Volóchinov (2017) e as ideias de Indursky (2016) nos apontam para outro conceito: o de interdiscursividade. Esse é um conceito caro aos estudos da linguagem, mais especificamente para a $\mathrm{AD}, \mathrm{e}$, por isso, entrará em nosso percurso a ser trilhado também. A interdiscursividade é compreendida como a relação dos discursos com outros discursos. Ela é a região de sentidos e de saberes em que há o encontro ou o confronto de vozes. A interdiscursividade é uma propriedade constitutiva da linguagem. Orlandi (2005) tem definido o interdiscurso como "a memória que que se estrutura pelo esquecimento, à diferença do arquivo que é o discurso documental, institucionalizado, memória que acumula" (ORLANDI, 2005, p. 59).

\section{Terceira parada: conceituando a intertextualidade}

Assim como a interdiscursividade é uma propriedade constitutiva da linguagem, a intertextualidade também o é em relação aos textos. Nessa parte deste texto, chegamos a outro ponto da trilha que me propus a percorrer. Primeiramente, o próximo passo será rumo ao conceito de intertextualidade proposto por Koch, Bentes e Cavalcante (2007), visto que foi esse o caminho traçado por mim em 2015. Posteriormente, semelhante ao que fiz na discussão sobre o discurso alheio, incorporarei outros fios discursivos a esse texto, trazendo outras reflexões também importantes.

Koch, Bentes e Cavalcante (2007), apoiadas em Genette, conceituam a intertextualidade como um diálogo entre textos. No entanto, as autoras ressaltam que esse diálogo ultrapassa uma unidade textual de análise, na medida em que pressupõe uma memória cultural para ser compreendido. Ainda, segundo Koch, Bentes e Cavalcante (2007), o fenômeno da intertextualidade pode ser explícito ou implícito. No primeiro caso, há referência explícita da autoria do texto base no interior do intertexto, como, por exemplo, o discurso relatado, as citações, as referências. Já no segundo caso, ocorre a implicitação da referência, ou seja, não há citação expressa da 
fonte, como ocorre nas paródias, por exemplo, e o leitor deve resgatar essa referência em sua memória cultural para produzir sentidos. No entanto, faço uma ressalva no que diz respeito a essa memória cultural, pois acredito que extrapola a dimensão do cultural, na verdade, minha defesa é de que se trata de uma memória discursiva, na qual ao colocar em cena como o dito vai ser repetido, o sujeito retoma a história do dito e projeta o futuro.

Indursky (2001) faz um deslocamento do conceito de intertextualidade da literatura, onde se deu a origem do termo, para a $\mathrm{AD}$ e defende que esse fenômeno não só aponta para o efeito de origem, ao trabalhar com discurso fundador, mas também, aponta, igualmente, para outros textos inscritos na mesma matriz de sentido, ou seja, a retomada de um texto pressupõe não só a retomada de um texto, mas de vários outros textos e discursos inscritos em uma rede de significações fundamentalmente dialógica e heterogênea, pois assim o são os textos e os discursos.

\section{Quarta parada: amarrando os conceitos}

Chegamos no ponto da trilha que era a peça-chave do artigo de 2015: após discorrer sobre os conceitos de "Discurso Alheio" proposto por Volóchinov (2017), e de "Intertextualidade", sob a perspectiva de Koch, Bentes e Cavalcante (2007), foi feita uma compilação, em forma de tópicos, salientando as aproximações que podem ser feitas entre os dois conceitos. Apresento a seguir, essa compilação, reformulada.

1) Pelo próprio conceito, percebemos que tanto a apropriação do discurso alheio, quanto a intertextualidade são fenômenos constitutivamente dialógicos e heterogêneos;

2) Ambos os conceitos pressupõem que o contexto sócio-históricopolítico-cultural-econômico do sujeito está diretamente relacionado à construção dos sentidos e, sendo assim, podemos perceber que os sentidos deslizam;

3) Os dois conceitos mantêm diálogo estrito com a exterioridade, que é a relação que se estabelece entre língua, sujeito e história e que 
fez emergir perguntas da seguinte natureza: "Que sujeito é esse que fala?", "De que lugar ele fala?”, "Que língua é essa que o sujeito fala?”.

4) Assim como na intertextualidade, a apropriação do discurso alheio pode se dar de forma implícita ou explícita. No entanto, é importante ressaltar que, mesmo quando essa apropriação é implícita, é possível apreendê-la no fio do discurso.

Estabelecidos os diálogos que os dois conceitos estabelecem entre si, passaremos, agora, para a penúltima parada da trilha: a ilustração dos fenômenos a partir dos poemas "Canção do Exílio", de Gonçalves Dias, e “Canção do Exílio”, de Murilo Mendes.

\section{Quinta parada: à guisa de ilustração}

Abaixo encontra-se um quadro em que os dois poemas estão colocados paralelamente e que permite uma comparação imediata entre eles:

Figura 1 - Poemas "Canção do exílio"

\begin{tabular}{|c|c|}
\hline Canção do Exilio & Canção do Exilio \\
\hline $\begin{array}{l}\text { "Minha terra tem palmeiras, } \\
\text { Onde canta o Sabiá; } \\
\text { As aves, que aqui gorjeiam, } \\
\text { Não gorjeiam como lá. } \\
\text { Nosso céu tem mais estrelas, } \\
\text { Nossas várzeas têm mais flores, } \\
\text { Nossos bosques têm mais vida, } \\
\text { Nossa vida mais amores. } \\
\text { Em cismar, sozinho, à noite, } \\
\text { Mais prazer encontro eu lá; } \\
\text { Minha terra tem palmeiras, } \\
\text { Onde canta o Sabiá. } \\
\text { Minha terra tem primores, } \\
\text { Que tais não encontro eu cá; } \\
\text { Em cismar - sozinho, à noite - } \\
\text { Mais prazer encontro eu lá; } \\
\text { Minha terra tem palmeiras, } \\
\text { Onde canta o Sabiá. } \\
\text { Não permita Deus que eu morra, } \\
\text { Sem que eu volte para lá; } \\
\text { Sem que desfrute os primores } \\
\text { Que não encontro por cá; } \\
\text { Sem qưinda aviste as palmeiras, } \\
\text { Onde canta o Sabiá." } \\
\text { Gonçalves Dias }\end{array}$ & $\begin{array}{l}\text { Minha terra tem macieiras da Califörnia } \\
\text { onde cantam gaturamos de Veneza. } \\
\text { Os poetas da minha terra } \\
\text { são pretos que vivem em torres de ametista, } \\
\text { os sargentos do exército são monistas, } \\
\text { cubistas, } \\
\text { os filósofos são polacos vendendo a } \\
\text { prestações. } \\
\text { gente não pode dormir } \\
\text { com os oradores e os pernilongos. } \\
\text { Os sururus em familia têm por testemunha a } \\
\text { [Gioconda } \\
\text { Eu morro sufocado em terra estrangeira. } \\
\text { Nossas flores são mais bonitas } \\
\text { nossas frutas mais gostosas } \\
\text { mas custam cem mil réis a düzia. } \\
\text { Ai quem me dera chupar uma carambola de } \\
\text { e ouvir um sabiá com certidão de idadel }\end{array}$ \\
\hline
\end{tabular}

Fonte: Brasil Escola, 2015. Acesso: 13 mai. 2015. 
Antes de começar uma análise, de fato, do poema, decidi trazer à baila algumas informações sobre seu contexto de produção e circulação que eu não havia feito no artigo de 2015. Novamente, essa escolha não é arbitrária, visto que dialoga com a discussão desenvolvida ao longo deste texto de que o contexto sócio-histórico-político-cultural-econômico é uma peça fundamental para construção de sentidos e que um texto carrega em si marcas de sua exterioridade, que consiste justamente na relação entre língua, sujeito e história. O poema "Canção de Exílio", de Gonçalves Dias, foi escrito em 1843 e publicado em 1846 no livro de poesias "Primeiros Cantos”. O período literário em que se inscreve o autor e suas obras é a primeira geração do Romantismo. Esse período ficou marcado pela busca de símbolos verdadeiramente nacionais que pudessem ser cantados em verso e prosa pelos jovens idealistas da época, que estavam motivados pela Proclamação da Independência do Brasil, um desses jovens era Gonçalves Dias. O discurso nacionalista surge, então, a partir das missões estrangeiras que vieram ao Brasil, na primeira metade do século XIX. Essas missões eram formadas por artistas e cientistas que coletavam espécimes e registravam através de desenhos e textos as características do país. Foram eles que apontaram os índios e a natureza exuberante como os símbolos mais representativos da identidade brasileira.

Feito esse movimento de contextualização, procederei à análise do primeiro poema. O eu lírico desse poema fala de um lugar de exílio. Esse contexto de enunciação pode ser verificado por meio dos dêiticos "aqui" e "lá": "as aves que aqui gorjeiam, não gorjeiam como lá" (grifo meu), sendo que o "aqui" refere-se ao lugar de onde o sujeito lírico fala e o "lá" ao lugar para onde ele olha e deseja estar. Vale mencionar que o contexto de enunciação do poema coincide com o contexto do poeta, Gonçalves Dias cursava Direito na Universidade de Coimbra. O eu lírico, por meio de seu discurso ufanista, apresenta uma imagem idealizada do Brasil, na qual as qualidades do Brasil são insuperáveis. A priori, há apenas uma comparação do que se encontra aqui e do que se encontra lá: "as aves que aqui gorjeiam não gorjeiam como lá/ Minha terra tem primores que tais eu não encontro cá. Em seguida, o eu lírico ressalta a superioridade do Brasil em relação ao país de exílio, ou talvez, a todos os outros países: "Nosso céu tem mais estrelas/ Nossas várzeas têm mais flores/ Nossos bosques têm mais vida/ Nossas vidas mais amores". É uma descrição de uma natureza exuberante, 
incomparável e longe dela, que pode ser entendida como uma metonímia de sua pátria, o eu-lírico sente-se deslocado, ele não estabelece uma relação de pertença com o país em que se encontra e roga a Deus que não o deixe morrer sem que volte a sua terra natal: "Não permita Deus que eu morra/ Sem que eu volte para lá/ Sem que desfrute os primores/ Que não encontro por cá/ Sem qu'inda aviste as palmeiras/Onde canta o Sabiá”.

Já o segundo poema, escrito por Murilo Mendes em 1930, está inscrito na segunda geração do Modernismo brasileiro. Esse período foi marcado por grandes acontecimentos históricos. Em âmbito internacional, houve a eclosão da Segunda Guerra Mundial, quando Hitler invadiu a Polônia e o crack da bolsa de Nova Iorque, em 1929. Este último acontecimento abalou a economia brasileira com a grande queda do preço do café no mercado internacional, o que desencadeou o rompimento entre as oligarquias cafeeiras paulistas e mineiras. São Paulo indicou Júlio Prestes para presidência e Minas Gerais reagiu apoiando o candidato da oposição, Getúlio Vargas. Júlio Prestes ganhou as eleições, mas não assumiu devido ao Golpe de Estado que colocou Vargas provisoriamente no poder. Era o fim da República Velha. Como se pode ver, o mundo inteiro enfrentava uma instabilidade social política e fez com que a literatura se repaginasse. Por volta de 1930, o Modernismo brasileiro atinge sua fase áurea, na qual os poetas afastaram-se um pouco do nacionalismo crítico e dedicaram-se a refletir sobre o mundo contemporâneo.

É justamente essa reflexão do mundo contemporâneo que está presente no poema de Murilo Mendes. O eu lírico faz uma crítica explícita e profunda à influência da cultura estrangeira na cultura brasileira. Isso fica claro na substituição que se tem dos elementos considerados símbolos nacionais, as palmeiras e o sabiá, são substituídos por elementos de outros países: "Minha terra tem macieiras da Califórnia/onde cantam os gaturamos de Veneza". O sentimento nacionalista do eu lírico vem associado a um inconformismo em relação à fácil assimilação das outras culturas e ao fato de o Brasil ter os olhos voltados para o exterior, pois o que de melhor é produzido, aqui, é destinado ao mercado externo, então, se a população local quer ter acesso a esses produtos, ela paga caro por isso, o que indigna o eu lírico e fica claro nos versos: "Nossas frutas são mais bonitas/nossas frutas são mais gostosas/mas custam cem mil réis a dúzia”. Esse eu lírico sente-se exilado em sua própria terra e deseja retomar seu sentimento de 
pertencimento ao seu país quando canta: "Aí quem me dera chupar uma carambola de verdade/ e ouvir um sabiá com certidão de idade!".

Koch, Bentes e Cavalcante (2007) postulam que a "a paródia se elabora a partir da retomada de um texto, que é retrabalhado para obter diferentes formas e propósitos em relação ao texto fonte. As funções discursivas dessa reelaboração podem ser humorísticas, críticas, poética etc.." (KOCH, BENTES E CAVALCANTE 2007, p. 137). Nessa medida, pode-se afirmar que o poema de Murilo Mendes é uma paródia do poema de Gonçalves Dias que envolve, constitutivamente, movimentos intertextuais e interdiscursivos que podem ser apreendidos no fio discursivo tecido por Murilo Mendes, como, por exemplo, utilizar a mesma estrutura sintática do poema-fonte: no poema de Gonçalves Dias, temos "Minha terra tem palmeiras onde cantam os sabiás", no de Murilo Mendes temos "Minha terra tem macieiras da Califórnia/onde cantam os gaturamos de Veneza". Novamente, no de Gonçalves Dias temos ““Nosso céu tem mais estrelas/ Nossas várzeas têm mais flores/ Nossos bosques têm mais vida/ Nossas vidas mais amores" e no de Murilo Mendes temos "Nossas frutas são mais bonitas/nossas frutas são mais gostosas/mas custam cem mil réis a dúzia”.

Murilo Mendes retoma o texto de Gonçalves Dias, apropriando-se do discurso nacionalista para (re)construir esse discurso para discutir o nacionalismo como se via naquele mometo. Como já mencionado acima, Murilo Mendes faz uma crítica severa ao processo de estrangeirismo no qual vivia o Brasil, onde, consequentemente, as riquezas naturais brasileiras não estavam sendo valorizadas pela nação. A princípio, podemos pensar que o autor está negando ou desidentificando-se com o discurso de Gonçalves Dias, mas, na verdade, seu objetivo é o de resgatar o sentimento nacionalista que havia se perdido. Há um deslocamento de sentido entre um poema e outro, no entanto, esse deslizamento não rompe com a posição-sujeito que Murilo Mendes assume, nem com a formação discursiva ufanista que molda os dizeres desse sujeito-autor e nem com o sentido primeiro de Gonçalves Dias. Os dois poemas "carregam traços discursivos que remetem a um mesmo espaço de memória e é isso que os une entre si” (INDURSKY, 2013, p. 96) (grifos da autora).

O processo de desidentificação que há no poema é com o discurso de estrangeirismo que ressoava no Brasil na época. Murilo Mendes coloca o sentido desse discurso em deriva para ascender outro discurso, com o qual 
se identifica: o sentimento nacionalista de valorização do que é próprio do país, que estava presente no poema de Gonçalves Dias, deve ser resgatado. Retomo Indursky (2016) para concluir os comentários a respeito do movimento de Murilo Mendes. O autor "realiza sua prática discursiva de escrita inscrevendo-se na discursividade (interdiscurso) e na memória de uma formação discursiva (memória discursiva).” (INDURSKY, 2016, p. 37)

\section{E a trilha chega ao fim...}

Percorrida toda a trilha, feitas todas as paradas, é chegada a hora de colocar um ponto final neste texto. Como já dito na primeira parada, esse ponto final nada mais é do que uma ilusão de que o texto está fechado, acabado, completo. E essa ilusão é necessária, senão que sentido faria escrever?

Este texto é intitulado "A PRÁTICA DISCURSIVA DA ESCRITA: entre a memória e o esquecimento" e esse título resume bem a minha proposta para ele. Abri o meu artigo de 2015, desestabilizei os sentidos que lá estavam postos, teci novos fios discursivos, incorporando-os aos outros que já havia tecido. Ao retomar o meu artigo, assumi minha posição sujeito-autor, inscrevi-me na ordem do interdiscurso e da repetibilidade, mobilizando minha memória discursiva, no entanto, necessitei, também, esquecer os sentidos que lá já estavam colocados para alinhavar novos fios discursivos.

O mesmo processo ocorreu com os poemas "Canção do Exílio", de Gonçalves Dias e Murilo Mendes. Murilo Mendes, ao retomar o poema de Goncalves Dias, assumindo sua posição sujeito-autor, inscreveu-se em um processo interdiscursivo e intertextual, ao retomar o discurso ufanista presente no poema de Gonçalves Dias e apropriar-se dos aspectos sintáticos do texto retomado. Nessa escrita, Murilo Mendes esqueceu os sentidos postos por Gonçalves Dias e incorporou novos sentidos, desestabilizando e colocando em deriva os sentidos outros do poema parodiado, com o propósito de fazer uma crítica profunda à influência da cultura estrangeira na cultura brasileira e de resgatar os sentimentos e valores nacionalistas. 
É importante fazer duas considerações: (i) na maioria das vezes, esse jogo entre a memória e o esquecimento se dá de forma inconsciente na prática discursiva da escrita; (ii) relembrando: a interdiscursividade é um processo constitutivo da linguagem, assim como a intertextualidade é um processo constitutivo do texto.

Ao abrir este texto, trouxe alguns dizeres de Orlandi (2001) que traduzem bem a trilha que eu me propus a percorrer, agora, peço licença para fechá-lo da mesma forma, trazendo dizeres, dessa vez de Indursky, para resumir a discussão que ensejei (e espero ter dado conta) fazer aqui: "A prática da escrita, como se pode ver, põe em jogo, no mesmo movimento, a memória discursiva com os sentidos já lá inscritos, que são retomados e/ ou rememorados, e o esquecimento, pois é preciso esquecer que os sentidos preexistem para poder dizer" (INDURSKY, 2016, p. 32).

\section{Referências}

CABRAL, Marina. Intertextualidade. Brasil Escola, c2021. Disponível em: https://brasilescola.uol.com.br/redacao/intertextualidade.htm. Acesso em 13 maio 2021.

FOUCAULT, Michel. Ordem do discurso (A). Edições Loyola, 1996.

FOUCAULT, Michel. As formações discursivas In: A Arqueologia do Saber. Tradução de Luiz Felipe Baeta Neves. $8^{a}$ edição, Rio de Janeiro: Forense Universitária, 2012.

INDURSKY, Freda. Da heterogeneidade do discurso à heterogeneidade do texto e suas implicações no processo da leitura. A leitura e a escrita como práticas discursivas. Pelotas: Educat, p. 27-42, 2001.

INDURSKY, Freda. O trabalho discursivo do sujeito entre o memorável e à deriva. Signo y seña, n. 24, p. 91-104, 2013.

INDURSKY, Freda. As determinações da prática discursiva da escrita. Revista Desenredo, v. 12, n. 1, 2016. 
KOCH, Ingedore G. Villaça. BENTES Anna Christina; CAVALCANTE, Mônica Magalhães. Intertextualidade: diálogos possíveis, v. 3, 2007.

ORLANDI, Eni Puccinelli. Discurso e texto. Campinas: Pontes, 2001. ORLANDI, Eni Puccinelli. Os efeitos de leitura na relação discurso/texto. In: Discurso e texto: formulação e circulação dos sentidos: no movimento dos sentidos. Campinas: Pontes, 2005, p.59-71

VOLÓCHINOV, V. Marxismo e filosofia da linguagem: problemas fundamentais do método sociológico na ciência da linguagem. Tradução, notas e glossário de Sheila Grillo e Ekaterina Vólkova Américo. São Paulo: Editora 34, 2017. 